\title{
UM PORTUGUÊS ENTRE EMIGRANTES E LETRADOS: A CHINA EM UMA CRÔNICA JORNALÍSTICA QUEIROSIANA
}

\author{
José Carvalho Vanzelli ${ }^{1}$
}

RESUMO: Apesar de nunca tê-la visitado, a China está presente em diversos textos de Eça de Queirós (1845-1900), tanto em sua obra ficcional quanto em seus textos jornalísticos. Neste trabalho pretendemos entender um pouco mais como Eça enxerga o Império do Meio. Para tanto, apresentamos uma leitura de "Chineses e Japoneses", publicado em Dezembro de 1894, parte integrante de Cartas Familiares e Bilhetes de Paris (1907).

PALAVRAS-CHAVE: Eça de Queirós, Extremo Oriente, Século XIX, Orientalismo, Imperialismo

\section{A PORTUGUESE AMONG EMIGRANTS AND LITERATES: CHINA IN A JOURNALISTIC CHRONICLE BY EÇA DE QUEIRÓS}

ABSTRACT: Despite never having visited it, China is present in several texts of the work of Eça de Queirós (1845-1900), both in his fiction and in his newspaper articles. In this work we intend to understand more as Eça sees the Middle Kingdom. Therefore, we analyse "Chineses and Japoneses" published in December 1894, part of Cartas Familiares e Bilhetes de Paris (1907).

KEYWORDS: Eça de Queirós, Far East, 19 $9^{\text {th }}$ Century, Orientalism, Imperialism

\footnotetext{
${ }^{1}$ Mestrando do programa de pós-graduação em Estudos Comparados de Literaturas de Língua Portuguesa da FFLCH-USP com o projeto "Eça de Queirós e o Extremo Oriente", sob a orientação da Profa. Dra. Aparecida de Fátima Bueno. E-mail: jose.vanzelli@usp.br
} 
Ao refletirmos sobre a relação entre Eça de Queirós (1845-1900) e a China, logo nos vem à mente sua obra $O$ Mandarim (1880). No entanto, essa relação não se resume apenas a essa obra ficcional. Como Beatriz Berrini (1992, p. 28) nos mostra em seus estudos, a China teve presença constante nos textos de Eça, embora o autor português nunca tenha visitado o Império do Meio (BERRINI, 1992, p. 30).

O primeiro contato entre a China e o autor d'O Mandarim se deu entre os anos de 1873 e 1874, quando este exerceu o cargo de cônsul português em Havana, então Antilhas Espanholas. Lá, teve que interceder por chineses que trabalhavam em um regime de escravidão em fazendas de proprietários espanhóis (BERRINI, 1993, p. 196). A situação dos trabalhadores asiáticos era responsabilidade da autoridade portuguesa na ilha devido às saídas se darem a partir do porto de Macau, então território lusitano. "De acordo com o regulamento de emigração daquela possessão, [os chineses] eram beneficiados da proteção consular portuguesa" (MAGALHÃES, 2000, p. 13), mesmo que suas origens fossem outras regiões da China continental. Após seu retorno à Europa, Eça produziu, em 1874, um relatório que só chegou ao público em 1979, sob o título de A Emigração como Força Civilizadora, em que analisa "as feições da emigração livre, a história dos seus movimentos, as suas causas, as suas consequências econômicas, as suas relações com o Estado, e a possibilidade da sua organização universal" (QUEIRÓS, 2000, p. 2084), dedicando-se também à emigração chinesa, "a mais célebre e a mais discutida das emigrações asiáticas" (QUEIRÓS, 2000, p. 2069).

A partir desse contato, Eça representou a China por diversas vezes, seja em seus textos literários, seja em suas crônicas jornalísticas. No campo da ficção, sua obra de maior fôlego é o já citado O Mandarim (1880). No entanto, referências constantes a leques, como no conto Singularidades de uma Rapariga Loura (1874); vasos, como em O Crime do Padre Amaro (1875) e O Primo Basílio (1878); e outros objetos decorativos são feitas. Ainda, existem diálogos com a cultura, política e religião chinesa ao longo de outras ficções, como, por exemplo, A Correspondência de Fradique Mendes (1900).

Já em seus textos de imprensa, o Império do Meio aparece em alguns artigos de política internacional. Estes tratam, principalmente, de questões que envolviam Inglaterra ou França, dois centros culturais e políticos da Europa oitocentista em que Eça trabalhou na função de cônsul de Portugal. Desses artigos, nos diz Elza Miné (2002, p. 32-33):

Eça não só [...] manteve [seus leitores] a par do que se passava em Inglaterra, na França, na Europa ou com elas se relacionasse, mas ofereceu-lhes propriamente uma interpretação de momentos, fatos, questões, hábitos, no exercício de um jornalismo eminentemente opinativo, que não apenas indiciava, insinuava ou deixava ver, mas que também explicitamente exibia marca de avaliação e julgamento.

Algumas das suas principais contribuições foram dadas à Gaz̧eta de Notícias do Rio de Janeiro, jornal no qual Eça publicou inúmeros textos entre os anos de 1880 e 1897 (MINÉ, 2000, p. 31). Foi enviado a esse jornal o artigo em que centraremos nossas atenções neste trabalho: "Chineses e Japoneses", publicado entre os dias 1 e 6 de dezembro de 1894. 
Nesta crônica, um dos principais, se não for o principal texto jornalístico escrito por Eça acerca do Extremo-Oriente, diversos assuntos são tratados. Listando alguns dos temas discutidos, temos a guerra entre a China e o Japão; a imagem dos europeus acerca dos povos asiáticos; simulação da visão chinesa acerca dos europeus; crítica à civilização europeia contemporânea, utilizando-se dessa mesma visão chinesa simulada; a rivalidade entre a China e o Japão; as possíveis consequências da guerra para a Europa; e a questão da emigração chinesa. Em meio a tantos temas e pontos críticos que estruturam o texto, acreditamos ser melhor dividi-lo para melhor compreendê-lo. Propomos analisar o escrito em duas partes. A primeira coincide com os trechos publicados nos dias 1, 2 e 3 de dezembro, de acordo com as informações presentes na Edição Crítica das Obras de Eça de Queirós. Textos de Imprensa IV (da Gazeta de Notícias) (2002), organizada pela profa. Elza Miné e pela profa. Neuma Cavalcante. Consequentemente, o que vamos, aqui, tratar como segunda parte engloba o conteúdo publicado nos dias 5 e 6 do mesmo mês.

A crônica se inicia com uma contextualização do que está acontecendo nas terras do Extremo-Oriente. O autor instrui seu "público duplo: europeu e americano" (GROSSEGESSE, 1997, p. 8) sobre a guerra entre Japão e China pelas terras na Coreia, episódio que ficou conhecido na história como 1ª . Guerra Sino-Japonesa (1894-1895). Durante essa contextualização, Eça começa a desnudar, com seu estilo irônico e através de "exageros grotescos de informações enciclopédicas" (GROSSEGESSE, 1997, p. 9), o estereótipo europeu acerca dos povos envolvidos na questão bélica. Eça apresenta a seu público os coreanos:

O que dele, na Europa, nós melhor conhecemos, por estampas, é a figura dos seus habitantes, homens esguios e graves, de longos bigodes pendentes, que usam o mais extraordinário chapéu [...] muito alto, muito pontiagudo e de abas tão vastas, que sob ele um patriarca pode abrigar toda a sua descendência, os seus móveis e os seus gados (QUEIRÓS, 2002, p. 527)

Os chineses:

Para o Europeu, o Chinês é ainda um ratão amarelo, de olhos oblíquos, de comprido rabicho, com unhas de três polegadas, muito antiquado, muito pueril, cheio de manias caturras, exalando um aroma de sândalo e de ópio, que come vertiginosamente montanhas de arroz com dois pauzinhos e passa a vida por entre lanternas de papel, fazendo vénias. (QUEIRÓs, 2002, p. 529)

E os japoneses:

E o Japonês é ainda para nós um magricela de crânio rapado, com dois enormes sabres enfiados na cintura, jovial e airado, correndo, abanando o leque, dissipando as horas fúteis pelos jardins de chá, recolhendo à casa feita de biombos e crisântemos para se cruzar numa esteira e rasgar o ventre! (QUEIRÓS, 2002, p. 529) 
Apenas nestas caracterizações irônicas, já se pode perceber uma crítica à visão europeia, que se torna clara nos parágrafos seguintes, quando Eça mostra que essa região do globo não é, para o europeu mediano, nada além de um "palco teatral anexo à Europa" (SAID, 1990, p. 73 apud LIMA, 1997, p. 81). Cito: "a luta da China e do Japão parece um enredo de mágica, ou o começo de um desses romances alegóricos, que tanto deleitaram o século XVIII” (QUEIRÓS, 2002, p. 528). E continua:

E, com efeito, para o grande público, para todos aqueles que não são profissionalmente diplomatas, sociólogos ou estratégicos, esta guerra entre as duas nações fortes do Extremo Oriente oferece apenas o interesse divertido de uma pantomima militar, passada numa região de fantasia, onde a política é dirigida pelas fadas e os príncipes picarescos. (QUEIRÓS, 2002, p. 528).

É interessante e importante também notar como Eça utiliza ora de uma aproximação, usando o pronome "nós", que "dá ideia de pensamento coletivo [...] e, ao mesmo tempo ironiza o seu próprio discurso" (OLIVA, 2008, p. 75), ora de um afastamento do "eu escritor" e do europeu, como em "Para o Europeu...", demonstrando consciência da limitação da visão europeia acerca dos povos do Extremo Oriente.

Assim, desde os primeiros parágrafos da crônica, Eça encerra uma crítica frontal à restrita visão difundida na Europa, mostrando-se ciente de que há, por trás do que é normalmente julgado e apresentado por seus concidadãos, uma complexa e antiga cultura. Eça diz claramente:

Hoje começamos realmente a compreender (com certas ressalvas) que se possa ser chinês. Mas esses povos da extrema Ásia, por ora só os conhecemos pelos lados exteriores e excessivos de seu exotismo. Com certos traços estranhos de figura e trajo, observados em gravuras, com detalhes de costumes e cerimônias, aprendidos nos jornais (artigos variedades) e sobretudo com o que vemos da sua arte, toda caricatural e quimérica - é que nós formamos a nossa impressão concisa e definitiva da sociedade chinesa e japonesa. (QUEIRÓS, 2002 p. 528-529).

À frente, continua expondo a limitação do pensamento europeu: "Porque os chineses não querem ter caminhos de ferros, nem fios de telégrafo, nem candeeiros de gás, que constituem para nós as expressões sumas da civilização, concluímos rasgadamente que são bárbaros" (QUEIRÓS, 2002 p. 529). Logo em seguida, nosso autor vai além, equiparando a cultura oriental à europeia, algo nem sempre comum na intelectualidade portuguesa da época ${ }^{2}$ :

Que por trás do rabicho e dos guarda-sóis de papel, e das caturrices, e de todo o exotismo, existam sólidas instituição sociais e domésticas, uma velha e copiosa literatura, uma intensa vida moral, fecundos métodos de

\footnotetext{
2 Para ilustrarmos, citamos o exemplo de Oliveira Martins, historiador, político importante e amigo próximo de Eça, que escreve em "Teoria da História Universal" (1884): "Não podemos tampouco supor que o europeu fique diante da civilização chinesa naquela atitude em que ficou outrora o grego bárbaro perante o Egito, pois além de que nada temos a aprender com a China, é ela que para a sua defesa adota os nossos navios" (MARTINS, p. 14 apud RAMOS, 2001, p. 67, grifo nosso)
} 
trabalho, energias ignoradas, o europeu mediano não o suspeita (QUEIRÓS, 2002, p. 529).

A crítica à Europa, que até então se dava ironicamente através da caracterização dos povos orientais, passa a ser feita de maneira direta, tendo por alvo o pensamento materialista e capitalista:

Quando uma civilização se abandona toda ao materialismo, e dele tira, como a nossa, todos os seus gozos e todas as suas glórias, tende sempre a julgar civilizações alheias segundo a abundância ou a escassez do progresso material, industrial, e sumptuário! Pequim não tem luz elétrica nas lojas; logo, Pequim deve ser uma cidade inculta. [...] Milhares, se não milhões de europeus não acreditam ainda, verdadeiramente, que os romanos e os gregos fossem povos civilizados, pois não conheciam a máquina a vapor, nem a máquina de costura, nem o piano, nem outras grandezas do nosso grande tempo (QUEIRÓS, 2002, p. 529-530).

Deste modo, o autor de Os Maias utiliza várias estratégias para mostrar sua tese. O que Eça parece nos dizer, até este ponto do texto, pode ser resumido da seguinte forma: o europeu não enxerga, principalmente por causa de sua política econômica, que há, nas terras do Extremo Oriente, povos com culturas "melhores ou tão boas como a dos ocidentais" (QUEIRÓS, 2002, p. 369), conforme expusera, no ano anterior, em um artigo publicado no mesmo jornal, intitulado "A França e o Sião" (1893).

Eça persiste nessa crítica por mais alguns parágrafos do texto, mostrando que é possível aprender algo com a China. Por exemplo, cita europeus a interagirem com o Império do Meio:

Os que [...] se internam pela China, vêm na realidade maravilhados: tendo ido para ensinar os operários chineses [...] confessam que aprenderam na convivência da burguesia culta e letrada, lições de conduta, de ordem, de respeito filial, de profunda união doméstica, de inteligente economia, de trabalho metódico, de subordinação, de pureza, de zelo moral e de toda a sorte de virtudes íntimas, que garantem melhor a grandeza, estabilidade e ventura de uma nação, do que a mais subtil arte em fabricar obuses e manobrar torpedeiros. (QUEIRÓS, 2002, p. 532-533).

Abrimos breves parênteses, aqui, para apontarmos algo que nos será útil em momento futuro de nosso estudo. No trecho supracitado, Eça de Queirós destaca uma classe letrada chinesa. Notamos aí, uma sociedade chinesa dividida em, no mínimo, duas classes: uma classe letrada (e nobre) e, em contraposição, uma classe iletrada, ou seja, a classe trabalhadora que Eça conviveu em Havana. Há uma relação direta desta elite letrada ao aprendizado. Ou seja, é o estrato social representado por uma imagem positiva, uma vez que pode ensinar algo ao europeu. Antônio Coimbra Martins (1967, p. 151), em seu estudo sobre $O$ Mandarim, destaca que a China, no imaginário oitocentista europeu, era representada como "ideal de arte, requinte, fantasia delicada e fino prazer". Aqui, entretanto, não podemos ligar essa representação, para Orlando Grossegesse (1997, p. 11) 
uma "imagem idealizante" ou "hiper-idealização", à China ou à cultura chinesa como um todo. Mas, esta visão positiva não deixa de estar presente em associação a um grupo social específico.

A visão de paridade cultural entre o ocidente e o oriente ganha seu ápice quando o romancista aproxima Paris e Pequim:

Só se queixam da falta de higiene municipal e da porcaria das ruas que [...] são tão mal varridas e tão abundantes em lixo como as de Paris há cinquenta ou sessenta anos, quando já o papá Hugo lhe chama de "cidade radiante", alma do mundo e toda a Europa lhe imitava. (QUEIRÓS, 2002, p. 533)

Então, Eça faz uma crítica direta ao imperialismo europeu, referindo-se aos conflitos conhecidos como a guerra do ópio (1839-1842 e 1856-1860). Do resultado da guerra, diz:

Depois de entrar vitoriosamente em Pequim [...], roubado e queimado o "Palácio de Verão", [...] A Europa força a China a abrir na sua carta cinco portos ao comércio europeu, aos algodões, às ferragens, às ninharias ocidentais, e sobretudo ao ópio, ao imenso ópio, a seis, sete milhões de quilos de ópio por ano! (QUEIRÓS, 2002, p. 533-534)

Mais uma vez surge a consciência crítica do escritor que enxerga no interesse meramente comercial o principal objetivo europeu por trás da guerra. Como consequência do conflito, o então cônsul português destaca a ida de chineses à Europa para aprender sua tecnologia. A partir daí, o autor d'Os Maias faz uma análise inversa do que havia mostrado até o momento. Em outras palavras, até agora o intelectual português caracterizou como o Europeu mediano enxergava as nações asiáticas. Agora irá simular o pensamento comum chinês acerca do Europeu, fazendo "uma reflexão em mão dupla" (OLIVA, 2008, p. 76):

O Chinês tem pelo Europeu um horror, de instinto e de razão, fisiológico e raciocinado, que está muito bem caracterizado numa página dos Anais Populares do Império em que se conta a primeira aparição dos holandeses em Macau, e nas vizinhanças de Cantão. "Estes homens (diz essa amarga narração) pertencem a uma raça selvática que habita regiões escuras e húmidas, e que nunca teve a vantagem de se relacionar $\mathrm{e}$ aprender com a China. São criaturas avermelhadas, de olhos azulados e estúpidos, e imensos pés de mais de um côvado. Parecem lamentavelmente ignorantes. E como aspecto exterior nada se pode imaginar de mais exótico e repelente!" Aí está a impressão que os bons flamengos (que nos parecem tão sólidos, sãos e limpos tipos de homens) fizeram aos Chineses. E os portugueses que nos fins do século XV apareceram nas costas da China, e os ingleses e franceses que vieram depois no rasto das nossas caravelas, não foram mais simpáticos aos filhos do Céu. (QUEIRÓS, 2002, p. 534)

Em seguida, traça como a civilização europeia aparenta ser incompreensível ao chinês, tendo como consequência o despertar de um sentimento patriótico e o repúdio ao 
estrangeiro. (QUEIRÓS, 2002, p. 535) A visão do europeu como “diabo estrangeiro" e o sentimento patriótico chinês não são novos em Eça. Em quase todos os textos em que o autor de $A$ Relíquia trata da China, esses pontos aparecem. Por exemplo, em um texto publicado no volume 2, número 2 da Revista de Portugal, datado de fevereiro de 1890 e com o título de "Notas do Mês", Eça exprime as mesmas ideias:

Nem os nossos progressos industriais, nem a nossa inteligência e ciência, constituem influências bastante fortes para deschinesar o chinês. Pelo contrário! Quanto mais nos conhece - menos respeita uma civilização que se lhe afigura singularmente tumultuosa e estéril [...] As nossas classes operárias e rurais parecem-lhe atrozes: - e os nossos conflitos sociais de capital e trabalho, uma rude e estúpida manifestação de barbárie (QUEIRÓS, 1995, p. 60).

Até este momento do texto, através dos trechos e citações aqui apresentados, vemos constantemente uma tentativa de equiparação entre a cultura europeia e a cultura chinesa. Não apenas demonstra saber que a civilização chinesa é mais complexa do que se julga normalmente no velho continente, mas às põe em pé de igualdade em diversos momentos, como na comparação de Paris e Pequim ou na demonstração de que uma visão estereotipada do "outro" está presente tanto no pensamento europeu comum, quanto na imagem chinesa acerca dos europeus, conforme se pode ver claramente nestes últimos dois trechos destacados.

Assim, até aqui, mostra-se, de um modo geral, um ponto de vista bastante favorável à civilização chinesa. No entanto, o texto não se encerra aí. Quando o romancista abandona sua caracterização do estereótipo chinês para o europeu (e vice-versa), e volta a tratar do conflito bélico entre a China e o Japão, o tom do discurso muda e, a partir deste ponto, se inicia o que, na nossa divisão, é a segunda parte do texto. Eça já havia dito:

O motivo por que se estão batendo chineses e japoneses não é o que particularmente nos interessa. [...] O que ardentemente nos deve ocupar, a nós europeus e a vós americanos, são as consequências da guerra. [...] A China vitoriosa seria a China readormecida. A China vencida - é a Europa ameaçada. (QUEIRÓS, 2002, p. 530).

A derrota da China levaria a uma inevitável diáspora de seus habitantes a nações da Europa e da América. Eça não retrata mais a China letrada, mas agora começa a falar dos trabalhadores, dos chineses que emigram atrás de trabalho. Baseado, principalmente, em sua experiência vivida em Havana, mas também com o conhecimento dos resultados da utilização de mão de obra chinesa em outras regiões do planeta, como os Estados Unidos e a Austrália, o romancista português passa a caracterizar esses trabalhadores.

Conjecturando a vitória do exército japonês, Eça prenuncia:

Mas virá, todavia, o homem amarelo! Virá muito humildemente, muito pacificamente, em grandes paquetes, com a sua trouxa às costas. Virá, não para assolar, mas para trabalhar. E é essa a invasão perigosa para o nosso velho mundo, a invasão surda e formigueira do trabalhador chinês (QUEIRÓS, 2002, p. 541). 
Passa, então, a tratar da questão da emigração chinesa. Para prever o futuro da Europa, caso fosse "invadida" por trabalhadores chineses, o autor recorda a experiência da Califórnia:

A Califórnia mostra [...] o que poderá ser, no nosso populoso continente, uma ilimitada vinda de chineses. Foi em 1852 que chegaram a São Francisco da Califórnia os primeiros cem chineses [...] Dez anos depois eram cem mil. Seriam hoje um milhão, muitos milhões deles, se o estado da Califórnia não os tivesse repelido como uma praga. (QUEIRÓS, 2002, p. 541)

Caracteriza esses trabalhadores, que conheceu em Cuba:

O Chinês não tem necessidades: uma única cabaia de chita ou lã grossa lhe basta para uma existência: um pouco de arroz e dois goles de chá o alimentam. Onde o branco, comilão e vicioso, precisa de ganhar dois mil réis por dia, o Chinês está feliz com três tostões, e acumula. (QUEIRÓS, 2002, p. 542)

Aponta suas qualidades: "tem admiráveis qualidades de trabalhador - pontualidade, atividade, docilidade, adaptação perfeita a todas as formas de serviços. São superiormente inteligentes e inacreditavelmente sofredores." (QUEIRÓS, 2002, p 542). Essas virtudes apontadas, até, sob certo ponto de vista, com certo exagero, fazem parte de outro tipo de "idealização" do povo chinês: o chinês incansável, inesgotável. Essa caracterização poderia preconizar um elogio ao trabalhador da China ou à utilização desta mão de obra em território estrangeiro, mas, na verdade, o que Eça quer dizer é que todas essas qualidades, na verdade, se tornam um grande problema nas nações europeias. Nosso autor destaca os problemas econômicos que um trabalhador assim causa: "Um imigrante com estas capacidades é terrível, sobretudo em países industriais, porque altera profundamente a balança dos salários" (QUEIRÓS, 2002, p. 543).

Ou seja, a utilização de trabalhadores chineses causa um grande desequilíbrio econômico às nações que os recebem. Por causa desse problema, de acordo com o romancista português, os chineses foram expulsos da Califórnia e sua entrada na Austrália foi proibida.

A caracterização do trabalhador chinês prossegue, sendo destacado que, ao chinês, não existem problemas de castigos físicos. Deste modo, para puni-lo é preciso cortar-lhe o "rabicho", símbolo de sua moralidade: "A sensibilidade nervosa do chinês é mínima. [...] Toda a sua sensibilidade é moral e, assim, na Havana, o castigo terrível e verdadeiramente doloroso que se impõe ao chinês é cortar-lhe o rabicho.” (QUEIRÓS, 2002, p. 542). Parece-nos que a representação de uma punição moral ser o maior castigo que o chinês pode receber é bastante difundida na Europa oitocentista, pois representações semelhantes aparecem no romance Tribulations d'un Chinois en Chine, de Julio Verne, publicado em 1879, um ano antes de $O$ Mandarim de Eça. 
Eça insiste na instabilidade econômica causada pelos orientais por mais alguns parágrafos, até que profetiza o caos em que o continente europeu se tornaria. Para concluir seu raciocínio, se dirige jocosa e diretamente ao público brasileiro. Cito:

Vós, amigos, aí no Brasil, parece que os desejais, para vos plantar e vos colher o café. Sereis inundados, submergidos. Virão cem, virão logo cem mil. Daqui a dez anos em São Paulo e no Rio tereis vastos bairros chineses, com tabuletas sarapintadas de vermelho e negro, fios de lanternas de papel, covis empestados de ópio, toda a sorte de associações secretas, uma força imensa crescendo na sombra, e cabaias e rabichos, sem cessar fervilhando. Mas tereis cozinheiros chineses, engomadores chineses - e sabeis enfim o que é uma sopa superlativamente sublime e um peitilho lustroso e digno dos deuses. Todas as outras colónias, portuguesa, italiana, alemã, serão insensível e subtilmente empurradas para as suas pátrias de origem - e o Brasil todo, em vinte anos, será uma China. (QUEIRÓS, 2002, p. 545)

Neste trecho final, o autor português não fala mais de questões econômicas. Eça aponta, agora, outro obstáculo social causado pelos emigrantes chineses: os problemas culturais. Ao prever "vastos bairros chineses" em São Paulo e no Rio de Janeiro e ao predizer que "o Brasil todo, em vinte anos, será uma China", parece-nos que Eça assegura que o chinês nunca se integra ao país para onde imigra, e, por fim, se fecha em uma colônia. $\mathrm{O}$ autor vai mais longe, ao dizer que os emigrantes chineses expulsam emigrantes de outros países. Portanto, o que Eça aparenta defender é que trazer trabalhadores chineses é transformar, aos poucos, seu país em uma segunda China. Esta imagem negativa dos trabalhadores chineses contrasta com aquela visão positiva da classe letrada, destacada anteriormente. Nesta parte do texto, o escritor parece não crer em um convívio harmônico entre os trabalhadores do Império do Meio e a população do país onde passam a viver.

Em 1896, Eça escreve um texto intitulado "A Propósito da Doutrina Monroe e do Nativismo", para o mesmo jornal carioca, em que defende a mesma ideia. Lá diz: "para onde quer que emigre (agora que emigra) o Chinês instala uma pequena China, onde vive de uma existência só chinesa, tendo já ao lado um esquife chinês para que apenas morto, o reconduzam dentro dele à grande China." (QUEIRÓS, 2000, p. 596).

O que vemos nesse trecho final de "Chineses e Japoneses" não é algo novo a Eça. Em A Emigração como Força Civilizadora, escrito vinte anos antes, o autor já destacava problemas econômicos e culturais decorrentes da utilização de mão de obra chinesa em colônias europeias. Lá dizia que "a heterogenia de raças não comporta fusão" (QUEIRÓS, 2000, p. 2082). Portanto vemos que, aparentemente, algumas ideias do autor de Os Maias em relação à China se mantiveram ao longo dos anos.

Querer alertar seu público brasileiro para essas consequências parece ser o verdadeiro motivo que leva Eça a escrever esta crônica em 1894. Com a abolição da escravatura no Brasil em 1888, foi largamente discutida a entrada de trabalhadores chineses para suprir a demanda de mão de obra. Intelectuais e governantes discutiram calorosamente essa possibilidade ao longo da década de 90 do século XIX (cf. OLIVA, 2008). Logo, Eça usa a guerra sino-japonesa como pretexto para desenvolver seu raciocínio 
e emitir o seu parecer sobre a questão da introdução de mão de obra chinesa em outros países, neste caso específico, o Brasil.

No entanto, se bem repararmos, o que soa, neste trecho final, como uma crítica a essa classe trabalhadora chinesa emigrante, na verdade, também serve como mais uma equiparação das atitudes chinesas e europeias em território estrangeiro. Ou seja, um movimento análogo ao realizado anteriormente. Explico. Eça, na primeira parte do texto, conforme destacamos, criticara os europeus que vão à China, mas, na verdade, não a adentram, julgando-a superficialmente. Isto é, mesmo em território chinês, o europeu vive de uma existência europeia, sem qualquer busca de diálogo, ensinamento ou aprendizagem. A mesma crítica se encerra aos chineses que emigram apenas em busca de trabalho, mas que vivem sem qualquer tipo de integração com o lugar em que estão e, assim, não tiram qualquer proveito de uma possível interação cultural.

Ao olharmos o texto de um modo geral, podemos identificar imagens da China que oscilam entre aspectos positivos e negativos. Resumindo brevemente, encontramos, principalmente, três aspectos que Eça descreve como representantes do Império do Meio: 1) uma imagem positiva, presente no imaginário oitocentista europeu que mostra a China ligada à classe letrada - enquanto uma civilização que pode ensinar aos Europeus, mas ignorada e subjugada por estes; 2) o chinês nativista; e 3) uma imagem negativa representada pelos emigrantes - que mostra os chineses como causas de problemas econômicos e culturais nos países ocidentais. No entanto, essas questões não se encerram em identificar um olhar positivo ou negativo da China por parte de Eça. Acreditamos que a questão é mais complexa. Entendemos, através dessas caracterizações feitas, que o ponto central do texto está no aprendizado. E, sob esse ponto de vista, tanto a Europa quanto a China são criticadas. Se, por um lado, Eça critica os europeus que não aprofundam seus conhecimentos sobre a China e a julgam pela "população iletrada e grosseira que se emprega nos misteres inferiores de barqueiro, carregador, criado moço de fretes, vendedores ambulantes, etc." (QUEIRÓS, 2002, p. 531), por outro também repreende os chineses emigrantes que, além de aceitarem trabalhar em condições desumanas e, assim, causar problemas de ordem econômica e cultural nos países que os acolhem, ainda se fecham em suas colônias e vivem de maneira isolada devido ao seu nativismo. A Europa e China são, no fundo, representadas de jeitos similares. A grande crítica de Eça parece se encerrar na falta de interesse mútuo, em que o chinês vai à Europa ou a outros lugares do mundo apenas em busca de trabalho e se tranca em suas colônias, enquanto o europeu vai à China, mas dela só quer um mercado consumidor para seus produtos e, consequentemente, o dinheiro. Nem os chineses tentam aprender algo com a Europa, nem os europeus com a China. A crítica de Eça mais profunda parece, então, não ser somente à limitação da visão do europeu mediano. Tampouco é uma condenação só ao povo chinês, causa de problemas econômicos e atritos culturais. A repreensão parece ser a ambos, Europa e China, ou seja, Ocidente e Oriente, que convivem, mas não interagem, não se interessam um pelo outro e, portanto, nada aprendem. A partir dessa percepção, podemos compreender a reprovação tanto à emigração asiática quanto à política capitalista do velho continente. 
Ainda, é interessante notar que Eça já enxerga, no final do século XIX, alguns pontos que os estudos de ciências humanas só vieram a teorizar ao longo do século XX. Obviamente, não estamos afirmando que o romancista português trata de questões referentes a este neocolonialismo, que só seria compreendido de maneira mais clara, principalmente, a partir da segunda metade do século XX, com toda a complexidade com que foi destrinçado no século passado. Entretanto, muitas das ideias que Eça apresenta vão ao encontro do que foi refletido com profundidade quase um século após sua morte. A fim de exemplificar, destacamos, aqui, dois desses pontos: o primeiro, ressaltado ao longo da análise de "Chineses e Japoneses", é a inteligência de Eça, que já notava que havia uma manipulação da representação dos povos e culturas do Oriente com o propósito de legitimar a política imperialista e colonialista que dominou o cenário político europeu até meados do século XX. As explanações e demonstrações do romancista português são consonantes com o que foi difundido, algumas décadas depois, nos estudos sociológicos de Edward Said; o segundo, é a perspicácia do autor em notar a importância da cultura nas relações internacionais. Afinal, toda a relação Europa-China destacada pelo autor lusitano, no fundo, nada mais é do que a evidência de um conflito cultural que influenciou não só a relação entre os países, mas também todo o processo de expansão do capitalismo desenvolvido ao longo dos últimos séculos.

Deste modo, parece-nos claro que a China encontrada nesta crônica jornalística queirosiana é, antes de qualquer coisa, plural. E, se considerada a situação de cidadão europeu de Eça, nascido e criado às luzes da educação europeia, muito mais complexa do que pode se julgar inicialmente. 


\section{REFERÊNCIAS BIBLIOGRÁFICAS}

BERRINI, Beatriz. "Introdução". In: Edição Crítica das Obras de Eça de Queirós. O Mandarim. Lisboa: Imprensa Nacional-Casa da Moeda, p. 15-74, 1992.

. "A China na Vida e na Obra". In: CAMPOS MATOS, A. Dicionário de Eça de Queiroz: 2a ed. Lisboa: Caminho, p. 193-200, 1993.

GROSSEGESSE, Orlando. "O fantasma do chinês deschinesado". In: Chineses e Japoneses. Lisboa: Fundação Oriente, p. 7-26, 1997.

LIMA, Isabel Pires de. Os Orientes de Eça de Queirós. In: Revista Semear. No 1. Rio de Janeiro: PUC-RJ, p. 81-95, 1997.

MAGALHÃES, José Calvet de. "Eça de Queirós, cônsul e escritor". In: Revista Camões, Lisboa: no. 9-10, p. 8-22, 2000.

MINÉ, Elza. "Imagens finisseculares do novo mundo no jornalismo de Eça de Queirós". In.: Actas do Congresso de Estudos Queirosianos - IV Encontro Internacional de Queirosianos. Vol. 1. São Paulo: Almedina, p. 31-42, 2000.

OLIVA, Osmar Pereira. "Machado de Assis, Joaquim Nabuco e Eça de Queirós e a imigração chinesa - qual medo?” In: Anais do XXI Congresso da ABRAPLIP, São Paulo: p. 66-84, 2008.

QUEIRÓS, Eça de. Edição Crítica das Obras de Eça de Queirós. Textos de Imprensa VI (da Revista de Portugal). Lisboa: Imprensa Nacional-Casa da Moeda, 1995.

. Chineses e Japoneses. Lisboa: Fundação Oriente, 1997.

"A Emigração como Força Civilizadora". In: BERRINI, B. (org.) Eça de

Queiroz. Obra Completa. Vol. III. Rio de Janeiro: Nova Aguilar, p. 1999-2084, 2000.

Edição Crítica das Obras de Eça de Queirós. Textos de Imprensa IV (da Gazeta de Notícias). Lisboa: Imprensa Nacional-Casa da Moeda, 2002. 